\title{
Efficient method of M-PSK demodulation based on particle filtering
}

\author{
Semenov V., Kruhlyk O. \\ Research and Development Department, Delta SPE LLC, \\ 123 Victory Avenue, 03179, Kiev, Ukraine
}

(Received 7 February 2019; Revised 28 March 2019; Accepted 29 March 2019)

\begin{abstract}
An efficient particle filtering algorithm for demodulation of M-PSK signals at the background of non-Gaussian noise is proposed. The state-space model of the observation signal is formulated including the dynamics of channel parameters' updating. The resulting estimation of informative symbols and channel parameters is done in two parallel contours. The simulations for QPSK signals have shown that for a sufficiently high number of particles the proposed method outperforms classical demodulation approach based on Gardner and Costas loops.
\end{abstract}

Keywords: blind particle filtering, QPSK (Quadrature Phase Shift Keying), Gardner loop, Costas loop.

2000 MSC: $65 \mathrm{C} 20,82 \mathrm{C} 80,94 \mathrm{~A} 14$

UDC: $519.673,654.165$

DOI: $10.23939 / \mathrm{mmc} 2019.01 .137$

\section{Introduction}

The problem of demodulation is of great interest in digital communications. The particle filtering recently found many applications in many communication tasks (see, e.g. review in [1]): blind equalization, blind detection over frequency non-selective dispersive channels, multiuser detection, estimation and detection of space-time codes in fading channels and others. Application of particle filtering to demodulation task has also received much attention (see, e.g. [2]). The key idea of particle filters is to use a stochastic grid approximation for the conditional probability distribution of the symbols with particles (values of the grid) evolving randomly in time. A comprehensive survey of the state-of-the-art particle filtering can be found in [3].

In this paper, the particle filtering algorithm is developed to solve the problem of demodulation for M-PSK signals (though the method can be applied to any kind of QAM signals). The results show that for a sufficiently high amount of particles the algorithm outperforms the classical demodulation method based on Gardner and Costas loops [4,5]. The structure of the paper is as follows. After the preliminary statements, we discuss particle filtering framework and how the demodulation task can be reduced to it. Then we present the demodulation algorithm and show experimental results.

\section{Preliminaries}

The model of received signal $z(t)$ has a form:

$$
z(t)=a e^{j(2 \pi f t+\varphi)} \sum_{k=-\infty}^{\infty} s(k) g(t-k T-\tau)+v(t),
$$

where $s(k)$ are transmitted symbols from alphabet $S$ (e.g. M-PSK symbols), $g(t)$ is pulse shaping (raised-cosine) filter, $T$ is a symbol period, $v(t)$ is the observation noise with variance $\sigma^{2} ; a, f, \varphi, \tau$ are channel's amplitude, carrier frequency, phase shift, and time delay respectively. 
Since demodulation is usually performed at multiple symbol rate, we are replacing model (1) by digital representation with a sampling period $T_{s}=T / m$ :

$$
z(p)=a e^{j\left(2 \pi f p T_{s}+\varphi\right)} \sum_{k=-\infty}^{\infty} s(k) g\left(p T_{s}-k T-\tau\right)+v(p),
$$

where notations $z(p)$ and $v(p)$ are hereinafter used instead of $z\left(p T_{s}\right)$ and $v\left(p T_{s}\right)$ for the simplicity of notations.

Note that by taking $p=m n, m n+1, \ldots, m n+m-1$, equation (2) can be rewritten in vector form

$$
\mathbf{z}(n)=a e^{j\left(2 \pi f n T_{s}+\varphi\right)} \mathbf{A}(\tau) \mathbf{s}(n)+v(n),
$$

where $\mathbf{s}(n)=[s(n-l) s(n-l+1) \ldots s(n) \ldots s(n+l-1) s(n+l)]$, matrix $\mathbf{A}(\tau)$ of size $m \times(2 l+1)$ represents the composition of following linear operations: raised-cosine filtering of vector $s(n)$, shift of resulting $(2 l m \times 1)$ vector on value $\tau$ and, finally, selection of (central) coordinates $l m+1, l m+$ $2, \ldots, l m+m-1$. Accordingly,

$$
\mathbf{z}(n)=[z(\ln +1), z(\ln +2), \ldots, z(\ln +m-1)]
$$

is the observations vector.

The goal is to obtain maximum a posteriori (MAP) estimates of transmitted symbols $s(n)$. The next section describes the particle filtering approach to the MAP estimation.

\section{Particle filtering framework}

Application of particle filtering requires representation of initial system is state space:

$$
\left\{\begin{array}{l}
\mathbf{x}(n)=f_{n}(\mathbf{x}(n-1), \mathbf{d}(n)) \\
\mathbf{z}(n)=h_{n}(\mathbf{x}(n), \mathbf{v}(n))
\end{array}\right.
$$

where $n$ is a discrete time step, $\mathbf{x}(n)$ is some state vector, $\mathbf{d}(n)$ and $\mathbf{v}(n)$ are the control vector and measurement noise vector respectively, $f_{n}$ and $h_{n}$ are some (generally, nonlinear) vector functions.

When the posterior probability of state vector is Gaussian, the task is standardly solved by such tools as Kalman filtering. However, in the case of non-linearity and non-Gaussian assumption these approaches are not efficient (see review [3]).

The key idea of particle filtering is to represent the required posterior density function by a set of random samples with associated weights and to compute estimates based on these samples and weights. As the number of samples becomes very large, this characterization becomes an equivalent representation to the usual functional description of the posterior power density function, and the resulting estimate approaches the optimal Bayesian estimate.

So, suppose that we have $n$ observations: $\mathbf{z}_{1: n}=[\mathbf{z}(1), \mathbf{z}(2), \ldots, \mathbf{z}(n)]$. Our goal is to maximize posterior probability $p\left(\mathbf{x}(n) / \mathbf{z}_{1: n}\right)$.

The key idea (the principle of importance sampling) is to approximate posterior density at discrete moment $k$ as

$$
p\left(\mathbf{x}(n) / \mathbf{z}_{1: n}\right)=\sum_{i=1}^{N_{s}} w_{n}^{i} \delta\left(\mathbf{x}(n)-\mathbf{x}^{i}(n)\right),
$$

where $\mathbf{x}^{i}(n)\left(i=1, \ldots, N_{s}\right)$ is a set of support points (particles) with associated weights $w_{n}^{i}$. The weights are calculated as

$$
w_{n}^{i}=\frac{p\left(\mathbf{x}^{(i)}(n) / \mathbf{z}_{1: n}\right)}{q\left(\mathbf{x}^{(i)}(n) / \mathbf{z}_{1: n}\right)},
$$

Mathematical Modeling and Computing, Vol. 6, No. 1, pp. 137-143 (2019) 
where $q(x)$ is an importance density, from which it is easier to draw samples as compared with $p(x)$. It can be shown that as $N_{s} \rightarrow \infty$, the approximation (4) approaches the true posterior density $p\left(\mathbf{x}(n) / \mathbf{z}_{1: n}\right)[3]$.

In [3] it was shown that weights can be calculated by recursive relation:

$$
w_{n}^{i}=w_{n-1}^{i} \frac{p\left(\mathbf{z}(n) / \mathbf{x}^{(i)}(n)\right) p\left(\mathbf{x}^{(i)}(n) / \mathbf{x}^{(i)}(n-1)\right)}{q\left(\mathbf{x}^{(i)}(n) / \mathbf{x}^{(i)}(n-1), z(n)\right)} .
$$

So, the realization of the algorithm depends on the choice of density $q(x)$. Although there many possible choices [3], it is often convenient to choose the importance density as

$$
q\left(\mathbf{x}^{(i)}(n) / \mathbf{x}^{(i)}(n-1), \mathbf{z}(n)\right)=p\left(\mathbf{x}(n) / \mathbf{x}^{(i)}(n-1)\right) .
$$

Substitution of (6) into (5) then yields

$$
w_{n}^{i}=w_{n-1}^{i} p\left(\mathbf{z}(n) / \mathbf{x}^{(i)}(n)\right) .
$$

Finally, the estimate at time step $n$ is

$$
\hat{\mathbf{x}}^{(i)}(n)=\frac{1}{N_{s}} \sum_{i=1}^{N_{s}} w_{n}^{i} \mathbf{x}^{(i)}(n) .
$$

It is known that the difference of the values of the importance weights becomes more and more distinct as the time increases. After a few steps, only a few particles have larger importance weights, and the weights of the other particles are almost zero. This phenomenon is called particle degeneracy or weight impoverishment. So, some resample methods [3] had been developed. The basic idea is that the particles with larger normalized importance weights will be multiplied, and the particles with lower normalized importance weights will be removed. In practice, a suggested estimation for degeneracy is denoted as

$$
N_{\mathrm{eff}}=\frac{1}{\sum_{i=1}^{N_{s}}\left(\bar{w}_{n}^{i}\right)^{2}}
$$

where $\bar{w}_{n}^{i}$ are the normalized importance weights at time step $n$. When the value of $N_{\text {eff }}$ is below a predefined threshold (taken as $N_{s} / 2$ ), the re-sampling process is performed. Suitable strategies for particles' resampling are described in [3].

\section{Application of particle filtering to demodulation task}

To apply the proposed particle methodology, we need to transform our model (2) into the state space form. Let us introduce the state vector:

$$
\mathbf{x}(n)=\{\mathbf{s}(n) \boldsymbol{\theta}(n)\}
$$

where

$$
\begin{aligned}
& \mathbf{s}(n)=\{s(n-l) s(n-l+1) \ldots s(n) \ldots s(n+l-1) s(n+l)\} \\
& \boldsymbol{\theta}(n)=\left\{a_{n}, \varphi_{n}, \tau_{n}, f_{n}, \sigma_{n}\right\} .
\end{aligned}
$$

Then the state equation can be expressed as

$$
\left\{\begin{array}{l}
\mathbf{s}(n)=\mathbf{F}_{s} \mathbf{s}(n-1)+\mathbf{d}_{s}(n) \\
\theta(n)=\mathbf{F}_{\theta} \boldsymbol{\theta}(n-1)+\mathbf{d}_{\theta}(n)
\end{array}\right.
$$


where $\mathbf{d}_{s}$ is a control vector, the coordinates of which take values from the symbols' alphabet $\mathbf{S}$, and $\mathbf{F}_{s}$ is the corresponding transition matrix:

$$
\mathbf{F}_{s}=\left[\begin{array}{ccccc}
0 & 1 & 0 & \ldots & 0 \\
0 & 0 & 1 & \ldots & 0 \\
\ldots & \ldots & \ldots & \ldots & \ldots \\
0 & 0 & 0 & \ldots & 1 \\
0 & 0 & 0 & \ldots & 0
\end{array}\right]
$$

The second equation in system (9) is required for the update of channel parameters' estimates. As will be shown in experimental section, without such an update, the values of parameters' estimates become "frozen" after a few time steps. We show that this problem can be eliminated by introducing the update of parameters' values due to second equation of system (9). We found that the transition matrix $\mathbf{F}_{\theta}$ can be taken as the unity matrix while the variances of components of vector $\mathbf{d}_{\theta}$ can be adjusted individually so that the continuous tracking of channel parameters values becomes possible. It means that the second equation of system (9) can be represented as follows:

$$
\left\{\begin{array}{l}
a_{n}=a_{n-1}+\beta_{a} d_{n}^{a} \\
\varphi_{n}=\varphi_{n-1}+\beta_{\varphi} d_{n}^{\varphi} \\
\tau_{n}=\tau_{n-1}+\beta_{\tau} d_{n}^{\tau} \\
f_{n}=f_{n-1}+\beta_{f} d_{n}^{f} \\
\sigma_{n}=\sigma_{n-1}+\beta_{\sigma} d_{n}^{\sigma}
\end{array}\right.
$$

where $d_{n}^{a}, d_{n}^{\varphi}, d_{n}^{\tau}, d_{n}^{f}, d_{n}^{\sigma}$ are the independent random values, each uniformly distributed over the interval $[-1,1]$. The parameters $\beta_{a}, \beta_{\varphi}, \beta_{\tau}, \beta_{f}, \beta_{\sigma}$ are selected to provide an adequate tracking of corresponding parameters' values and to keep high quality (in terms of signal-to-noise ratio) of demodulation of signal $s(n)$. The selection of their specific values and the example of corresponding tracking of parameter are given in the experimental section.

Note that this update of parameters was not used in other known to us works such as [6], where the second equation in system (9) was given simply as $\theta(n)=\theta(n-1)$. In the experimental section the efficiency of this innovation is shown.

Further, the observation equation is obtained due to (3)

$$
\mathbf{z}(n)=a_{n} e^{j\left(2 \pi f_{n} n T_{s}+\varphi_{n}\right)} \mathbf{A}\left(\tau_{n}\right) \mathbf{s}(n)+\mathbf{v}(n) .
$$

Based on equations (9), (10), we can run the following particle algorithm for the demodulation task.

1. Initialization. For $i=1, \ldots, N_{s}$ draw a set of particles $\mathbf{x}_{0}^{i}=\left\{\mathbf{s}_{0}^{i}, \theta_{0}^{i}\right\}$ according to a priori information and assign weight $w_{0}^{i}=1 / N_{s}$ for each particle.

2. Draw the particles $\mathbf{x}_{n}^{i}=\left\{\mathbf{s}_{n}^{i}, \theta_{n}^{i}\right\}$ at time $n$ based on particles from previous state $\mathbf{x}_{n-1}^{i}=$ $\left\{\mathbf{s}_{n-1}^{i}, \theta_{n-1}^{i}\right\}$ in accordance with (9).

3. Update the weights by formula (7) and normalize them.

4. Calculate the estimate of transmitted symbols and channel parameters by (8).

5. If $N_{\text {eff }}<0.5 N_{s}$, perform particles resampling.

Due to the nature of the system (9), the estimation of informative symbols and channel parameters is done in two parallel contours.

\section{Experimental results}

In order to assess the performance of the proposed method, we applied it to the case of QPSK signals demodulation at the presence of non-Gaussian background noise. The resulting demodulation method 
was compared with classical demodulator based on Gardner and Costas loops [4,5]. Preliminary the empirical constants of Gardner \& Costas algorithm were optimized to achieve the optimal performance.

To compare the two methods, we tried 500 packets of 512 bits (256 QPSK symbols) for different signal-to-noise ratios (SNR). Following the works [2,6], we modeled non-Gaussian noise as the weighted sum of two Gaussian probability densities:

$$
p(v)=\mu N\left(0, o^{2}\right)+(1-\mu) N\left(0, k \sigma^{2}\right),
$$

where the values $\mu=0.2, k=10$ are taken.

Different numbers of particles were tried: $N_{s}=100,1000,10000$. We also used $m=2$ as an interpolation index and $f_{s}=1 / T_{s}=46800 \mathrm{~Hz}$ as the sampling frequency. During numerical modulation the values responsible for update of parameters $\beta_{a}, \beta_{\varphi}, \beta_{\tau}, \beta_{f}, \beta_{\sigma}$ were chosen as follows: $\beta_{a}=0.1$, $\beta_{\varphi}=0.03, \beta_{\tau}=0.04, \beta_{f}=9 \times 10^{-5}, \beta_{\sigma}=0.02$. The results for the frequency errors $f=0$ and $f=0.001 f_{s}$ are presented in Figs. 1 and 2 respectively.

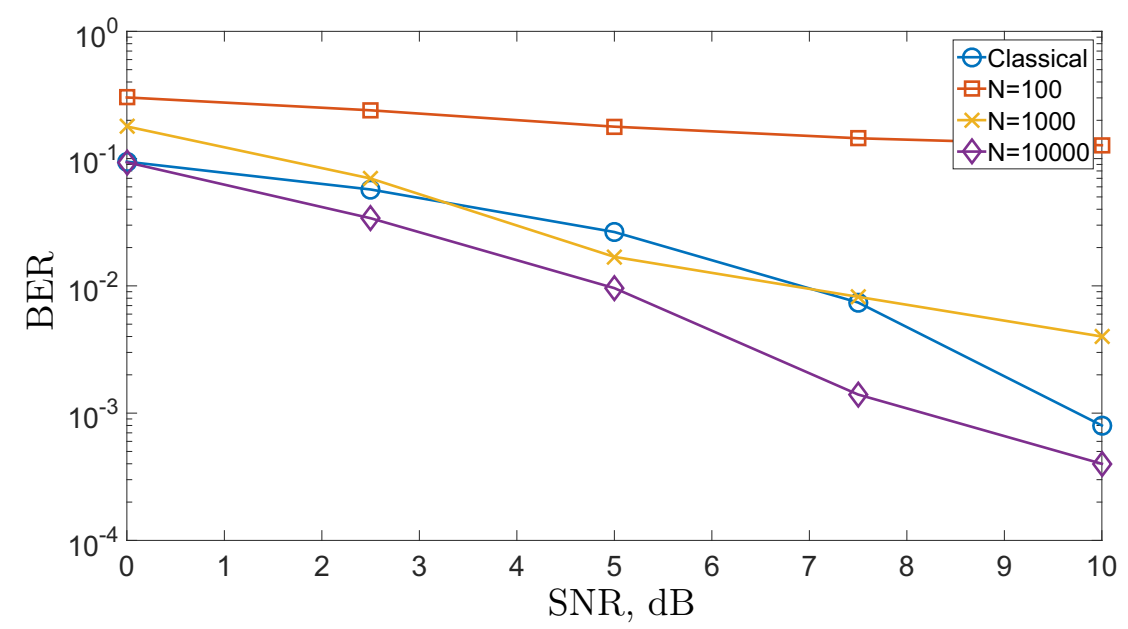

Fig. 1. Comparison of BER provided by classical demodulator $[4,5]$ with modifications of proposed method for $f=0$.

From the Figs. 1, 2 it can be seen for $N_{s}=10000$ the proposed algorithm outperforms the existing method in terms of BER. At the same time, classical demodulator works better than particle approach for 100 and 1000 particles. It shows the importance of choosing the proper amount of particles for the correct demodulation.

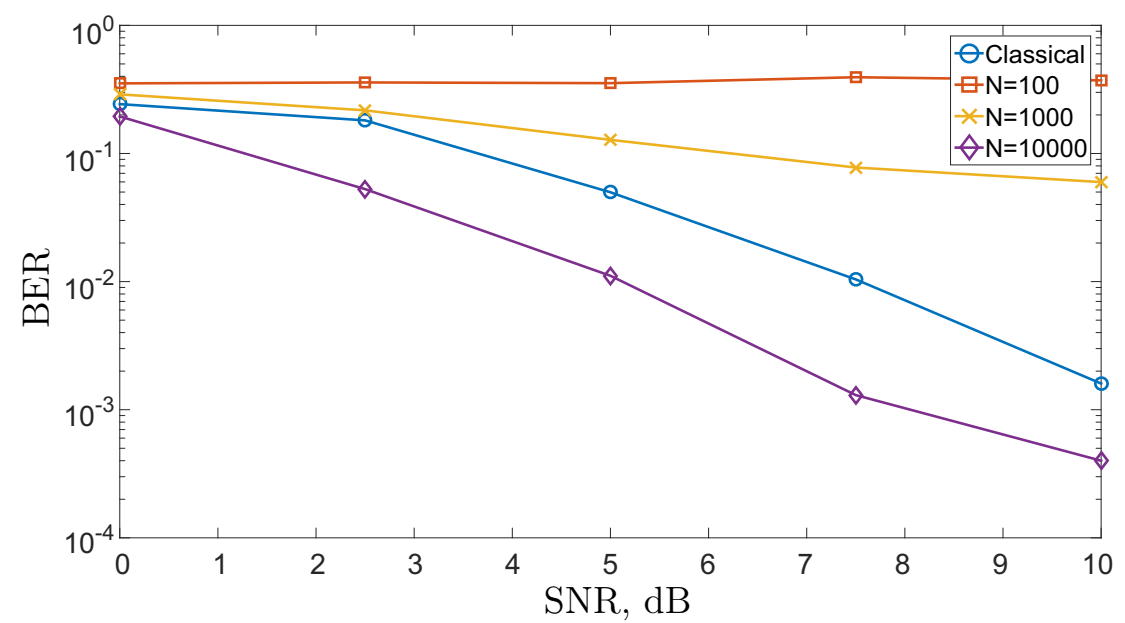

Fig. 2. Comparison of BER provided by classical demodulator $[4,5]$ with modifications of proposed method for $f=0.001 f_{s}$. 
Note that without the introduction of parameters' update by vector $d_{\theta}$ in (9), the continuous update of channel parameters does not take place. A typical example is shown in Fig. 3. The upper plot shows the tracking of cyclic frequency in the absence of matrix $F_{\theta}$, where one can observe the "freezing" of parameter's update. At the same time, the bottom plot corresponds to the case of update of channel parameters and here one can observe the convergence to the true cyclic frequency value.

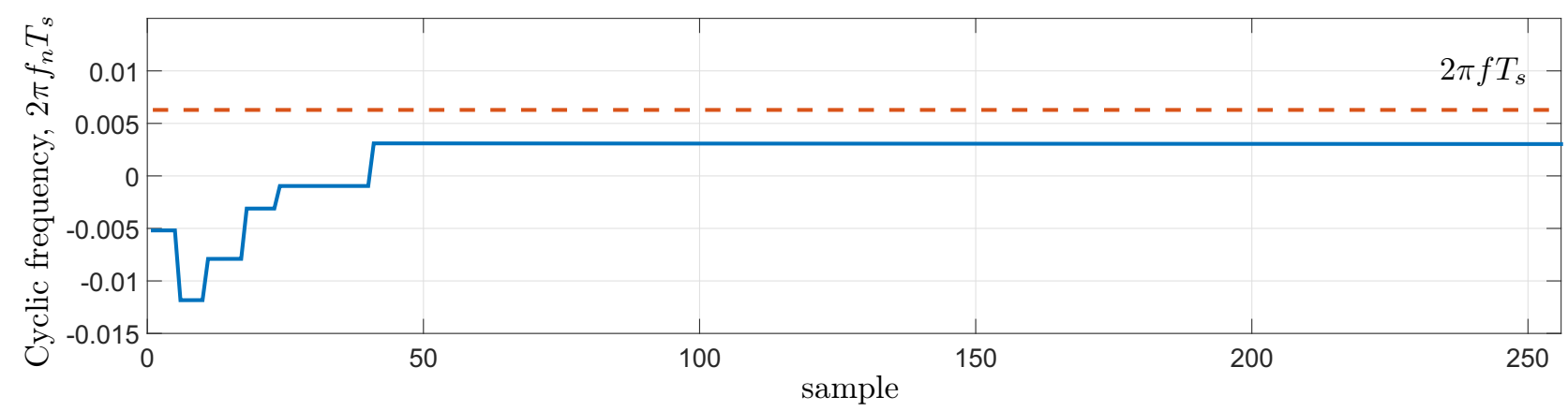

$a$

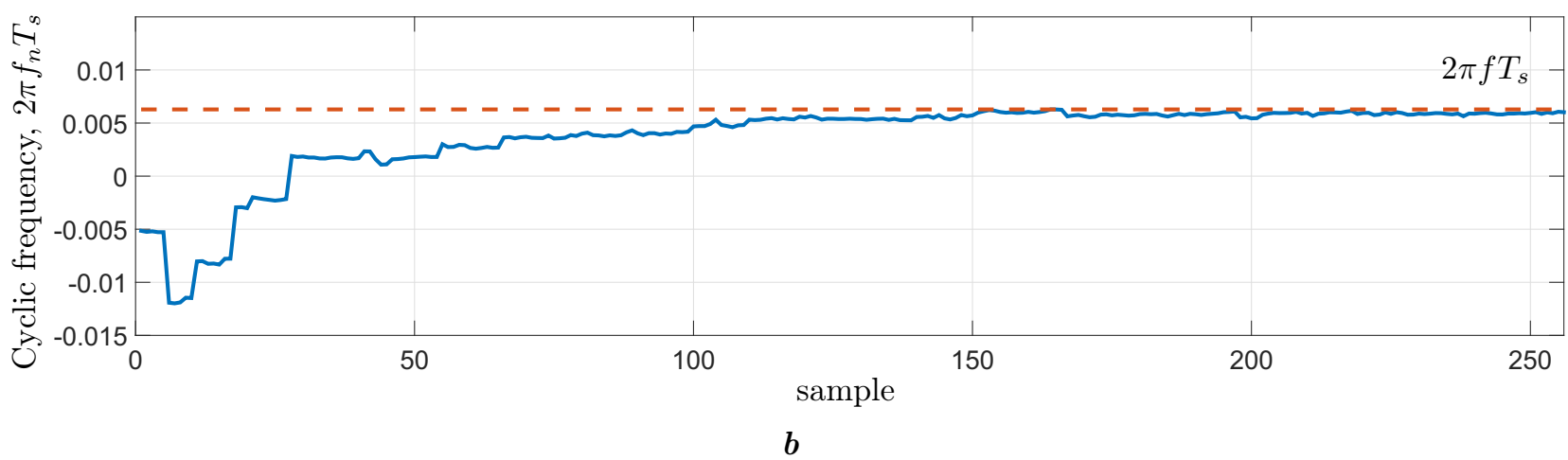

Fig. 3. Tracking of frequency parameter without $(\boldsymbol{a})$ and with $(\boldsymbol{b})$ the update of channels' parameters.

\section{Conclusions}

In this paper, we have proposed the particle filtering algorithm for demodulation of signals at the background of non-Gaussian noise. The proposed state model of observation signal includes dynamics of channel parameters' updating and this innovation has been shown to be effective. The simulations for QPSK signals at different noise levels have shown that BER decreases with the growth of number of particles. Besides, for the sufficiently high number of particles (10000), the proposed method outperforms classical demodulation approach based on Gardner and Costas loops.

[1] Djuric P. M., Kotecha J.H., Zhang J., Huang Yu., Ghirmai T., Bugallo M.F., MiguezJ. Particle filtering. IEEE Signal Proc. Magazine. 20 (5), 19-38 (2003).

[2] Punskaya E., Andrieu C., Doucet A., Fitzgerald W. J. Particle Filtering for Demodulation in Fading Channels with Non-Gaussian Additive Noise. IEEE Trans. Comm. 49 (4), 579-582 (2001).

[3] Arulampalam M. S., Maskell S., Gordon N., Clapp T. A tutorial on particle filters for online nonlinear/nonGaussian Bayesian tracking. 50 (2), 174-188 (2002).

[4] Feigin J. Practical Costas loop design. RF design. 25, 20-36 (2002).

[5] Gardner F. M. A BPSK/QPSK timing error detector for sampled receivers. IEEE Transactions on Communications. 34 (5), 423-429 (1986).

[6] Hua Zh., Youguang Zh., Guoyan Li. Particle-Filtering-Based Approach to Undetermined Blind Separation. Advances in information Sciences and Service Sciences. 4 (6), 305-313 (2012). 


\title{
Ефективний метод демодуляції M-PSK-сигналів на основі багаточасткової фільтрації
}

\author{
Семенов В., Круглик О. \\ Науково-дослідний відділ алгоритмів, ТОВ “Дельта СПЕ", \\ проспект Перемоги, 123, Київ, 03179, Україна
}

\begin{abstract}
Запропоновано ефективний алгоритм демодуляції M-PSK-сигналів у присутності негаусівського шуму на основі багаточасткової фільтрації. Побудовано модель спостережуваного сигналу, що враховує динаміку зміни параметрів каналу зв'язку. У результаті цього, оцінювання інформативних символів та параметрів каналу здійснюється двома незалежними контурами. Моделювання на прикладі QPSK-сигналу продемонструвало, що, за умови використання достатньої кількості часток, запропонований метод ефективніший порівняно із класичним підходом до демодуляції з використанням петель Гарднера і Костаса.
\end{abstract}

Ключові слова: сліпа багаточасткова фільтрачія, QPSK (квадратурна фазова маніпуляиія), петля Гарднера, петля Костаса.

2000 MSC: $65 \mathrm{C} 20,82 \mathrm{C} 80,94 \mathrm{~A} 14$

Удк: $519.673,654.165$ 